\title{
Analysis of Complications After Button Battery Ingestion in Children
}

\author{
Ágnes Varga, MD, * Tamás Kovács, MD, PhD, * and Amulya K. Saxena, MD, PhD, DSc, FRCS(Glasg)†
}

\begin{abstract}
Aim: Button battery ingestion (BBI) in children may cause severe complications. This analysis is a literature review of complications after pediatric BBI. Methods: Literature was searched on PubMed (1995-2015) using the terms "button battery," "ingestion," and "children." End points were age, type and diameter of battery, complications, affected organ, and fatality.

Results: A total of 31 publications were analyzed. Patients from 4 months to 19 years old were included $(n=136,191$, with $n=102,143$ or $75 \%$ aged $<6$ y). In 6262 , the diameter of the battery was documented. Batteries of $20 \mathrm{~mm}$ or greater in size were more prone to complications $(n=226)$. With regard to the anatomy, BBI caused complications mainly in the esophagus $(\mathrm{n}=88,38.94 \%)$. Sixty-one fatal outcomes were reported.

Conclusions: Children younger than 6 years are the most prone to BBI, with lithium batteries of $20 \mathrm{~mm}$ or greater in size associated with complications. Complications have been estimated at $0.165 \%$, with lethality of $0.04 \%$. The esophagus is the most affected organ, but vascular involvement is often fatal.
\end{abstract}

Key Words: button battery, ingestion, complications

(Pediatr Emer Care 2018;34: 443-446)

B utton battery ingestion $(\mathrm{BBI})$ poses an important hazard to children and is responsible for increased hospital visits in the recent decade. ${ }^{1}$ Individual centers have limited cases to have a sufficient sample size to evaluate outcomes. Hence, a literature-based analysis of complications and outcomes of BBI was performed. In most of the cases, the course is benign and the battery passes through the gastrointestinal tract uneventfully. However, lodged button batteries can cause severe complications ${ }^{2,3}$ and even death., The incidence was reported to be fluctuating, but the outcomes worsened. ${ }^{4,6}$ Not witnessed ingestions and nonspecific symptoms and signs often lead to misdiagnosis or late diagnosis. ${ }^{7}$

\section{METHODS}

A 20-year period search was performed on PubMed for the terms "button battery," "ingestion," and "children." Seventy-two articles matched the search criteria. Of these, 63 articles published between 1995 and 2015 were reviewed. Non-English articles and articles dealing with adult populations were excluded, which finally resulted in 31 publications ( 7 articles and 24 case reports/ series) that were analyzed.

End points of the study were age of the patients, type and diameter of the battery, complications, affected organ, and fatal outcomes.

\section{RESULTS}

The data analysis included 136,191 children who visited emergency departments because of BBI. Patient age ranged from

From the *Division of Pediatric Surgery, Department of Pediatrics, University of Szeged, Szeged, Hungary; and $\dagger$ Department of Pediatric Surgery, Chelsea Children's Hospital, Chelsea and Westminster NHS Foundation Trust, Imperial College London, London, United Kingdom.

Disclosure: The authors declare no conflict of interest.

Reprints: Ágnes Varga, MD, Division of Pediatric Surgery, Department of

Pediatrics, University of Szeged, Korányi Fasor 14-15, 6725 Szeged,

Hungary (e-mail: agivarga213@gmail.com).

Copyright (C) 2018 Wolters Kluwer Health, Inc. All rights reserved.

ISSN: 0749-5161
4 months to 19 years. Three fourths of the patients were younger than 6 years $(n=102,143)$. Regarding the single-year age group, 1 -year-old patients had the greatest number $(n=10,961)$.

One of the primary end points was the type of battery, and 5 varieties were identified. Metal type was documented in $\mathrm{n}=5984$ (4.39\%). Of the cases, alkaline batteries were found to be most frequently ingested in $\mathrm{n}=2602$ (43.48\%); zinc-air, in $\mathrm{n}=1980$ $(33.09 \%)$; silver oxide, in $\mathrm{n}=816(13.64 \%)$; lithium, in $\mathrm{n}=583$ (9.74\%); and mercury, in $\mathrm{n}=3(0.05 \%)$.

In 6262 cases, the diameter of the battery was documented. Batteries were $10 \mathrm{~mm}$ or smaller in $\mathrm{n}=2055(32.82 \%), 11$ to $15 \mathrm{~mm}$ in $\mathrm{n}=3368(53.78 \%), 15$ to $20 \mathrm{~mm}$ in $\mathrm{n}=416(6.64 \%)$, and $20 \mathrm{~mm}$ or larger in $\mathrm{n}=423(6.76 \%)$. Although more than $90 \%$ of the batteries swallowed were less than $20 \mathrm{~mm}$ in size ( $\mathrm{n}=5839,93.24 \%$ ), batteries of $20 \mathrm{~mm}$ or greater in size $(\mathrm{n}=423,6.76 \%)$ caused more complications.

The types of complications were next analyzed, and ulceration or perforation of the gastrointestinal tract was found to be the most frequent. Severe complications such as vascular involvement appeared in $6 \%$. However, rare complications were also reported, such as bilateral vocal cord palsy or spondylodiscitis. The following complications $(\mathrm{n}=226)$ were reported: ulceration $(\mathrm{n}=50,22.1 \%)$, necrosis $(\mathrm{n}=11,4.9 \%)$, perforation $(\mathrm{n}=41$, $18.1 \%)$, stricture/obstruction $(\mathrm{n}=31,13.7 \%)$, bilateral vocal cord palsy due to recurrent nerve damage $(\mathrm{n}=5,2.2 \%)$, tracheoesophageal fistula formation ( $\mathrm{n}=33,14.6 \%)$, bronchopneumonia $(\mathrm{n}=1,0.4 \%)$, spondylodiscitis $(\mathrm{n}=1,0.4 \%)$, and vascular involvement $(\mathrm{n}=14,6.2 \%)$, as well as reasons unknown $(\mathrm{n}=39,17.2 \%)$ (Fig. 1). It was important to note that batteries larger than $20 \mathrm{~mm}$ were responsible for these complications. Gastrointestinal structures were more often involved in complications. With regard to the anatomy, BBI caused complications mainly in the esophagus ( $\mathrm{n}=88$, $38.94 \%)$, stomach $(\mathrm{n}=16,7.08 \%)$, small intestine $(\mathrm{n}=3,1.33 \%)$, and pharynx $(\mathrm{n}=2,0.88 \%)$; however, nasal cavity $(\mathrm{n}=36$, $15.93 \%$ ) led the list in the respiratory manifestation, followed by trachea $(n=1,0.44 \%)$ and unknown $(n=80,35.40 \%)$ (Fig. 2$)$.

The time required for passing the battery with stool spontaneously was documented only in 4903 patients. Almost three quarters of the ingested batteries passed spontaneously within 4 days $(\mathrm{n}=3644,74.32 \%)$. Endoscopy as a therapeutic option in 8020 cases was documented - whether it was performed or not. Endoscopic removal was necessary in $n=677$ (8.44\%). Complications occurred in 226 cases; almost half of them $(n=100$, $44.23 \%$ ) needed an open surgery, mainly to treat the complications. There were 61 fatal outcomes reported due to massive hemorrhage because of fistula formation to the great vessels (aortoesophageal fistula, right subclavian artery-esophageal fistula, esophageal-inferior thyroid arteries and veins) $(\mathrm{n}=27$, $44.3 \%$ ) or suffocation secondary to blood aspiration and bronchopneumonia $(\mathrm{n}=7,11.4 \%)$. In 27 cases $(44.3 \%)$, the cause of death is unknown (Fig. 3).

\section{DISCUSSION}

Although BBI is a common referral to the emergency department, the documentation is scarce with regard to the type of battery, size, and exact details of the type of complications. Button 


\section{$n=226$}

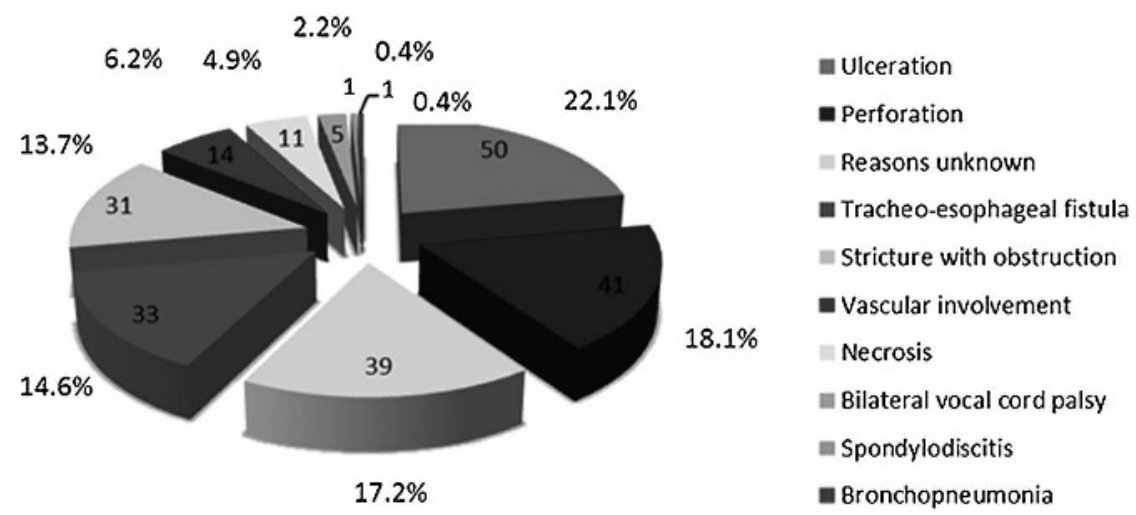

FIGURE 1. Pie chart showing the distribution and percentage of reported complications in the pediatric population after BBIs.

battery ingestion is more frequent among children younger than 6 years, with a peak at 1 year old. Because they are usually nonverbal and the size of the battery is relatively larger, this group is more vulnerable. According to Litovitz et $\mathrm{al}^{4}{ }^{4}$ it remains unknown whether the chemistry of the battery influences the outcome, because there is only a small number of cases available of nonlithium battery ingestions with a diameter of $20 \mathrm{~mm}$ or larger. Although the incidence of BBI has been fluctuating, there is no clear incidence trend observed. However, the number of severe complications and fatal injuries has shown a 6.7-fold increase in 25 years. ${ }^{6}$ The increase of complications and fatal injuries has been mostly attributed to the 20 -mm-diameter lithium cells. Although small batteries were more often ingested, larger batteries caused the complications because they were more prone to getting lodged and these lithium cells had twice the voltage $(3 \mathrm{~V})$ compared with the other $(1.5-\mathrm{V})$ batteries. ${ }^{4,6}$ Furthermore, $3-\mathrm{V}$ 20 -mm lithium button batteries generate more current, which in turn causes more rapidly developing tissue damage. ${ }^{4,6}$ The mechanism of the injury is induced by 4 factors: (1) electrical discharge, (2) pressure necrosis, (3) leakage of alkaline content, and (4) metal toxicity. 8,9

When the battery's negative pole makes contact with a conductive medium (lining of the esophagus), external electric current is generated that hydrolyzes tissue fluid, produces hydroxide accumulation, and causes corrosive tissue injury. A helpful mnemonic is the $3 \mathrm{Ns}$, which states that current generates hydroxide production at the negative buttery pole that is narrow and causes necrosis. ${ }^{4}$ This is the most important mechanism that is responsible for the injuries caused by $20-\mathrm{mm}$ lithium cells. The ischemic necrosis also develops because of physical pressure. ${ }^{4,10,11}$ In case of alkaline batteries, the alkaline electrolyte leakage from the battery causes caustic necrosis. (Lithium cells do not contain alkali but rather a mildly irritating organic electrolyte solution, leakage of which does not cause severe tissue damage. ${ }^{4,10}$ Rash due to nickel allergy may occur, but significant poisoning was not reported because mercuric oxide batteries have been banned since 1996 . $^{4,11,12}$

The greatest concern is the extremely narrow, 2-hour time window. Batteries lodged in the esophagus can cause severe burns in only 2 hours. ${ }^{4}$ Symptoms are nonspecific, such as fever, cough, irritability, and dysphagia. Irritability, anorexia, melena, and dysphonia can occur in infants; fever, dyspnea, coughs, stridor, drooling, and vomiting can occur in toddlers; and children older than 5 years can describe abdominal or thoracic pain. ${ }^{13}$ Owing to nonspecific symptoms and unwitnessed cases, ${ }^{14}$ nonverbal children ${ }^{15}$ physicians can miss the diagnosis and establish gastroenteritis, respiratory tract infection (laryngitis, tracheobronchitis), or other infections. ${ }^{13,16-18}$ Attention should also be paid to the diagnosis because, on chest $\mathrm{x}$-ray, button batteries can be mistaken for coins, ${ }^{11,19,20}$ electrocardiogram electrodes, or other external objects. ${ }^{4,21}$ In this respect, button batteries have typical appearance on lateral radiograph: the step-off sign and, on posterior-anterior view, a double-density or double-ring shadow. ${ }^{11,22-24}$ Because most batteries pass spontaneous within 4 days, they can be left in the stomach in an asymptomatic patient, with repeated x-ray after 4 days. ${ }^{4}$ Co-ingested magnets and batteries need prompt removal because the stomach or intestine wall might be trapped between them and cause ulceration and tissue necrosis. ${ }^{25}$

If the battery is in the esophagus, urgent endoscopic removal is necessary. Delays because of limited access to endoscopists,

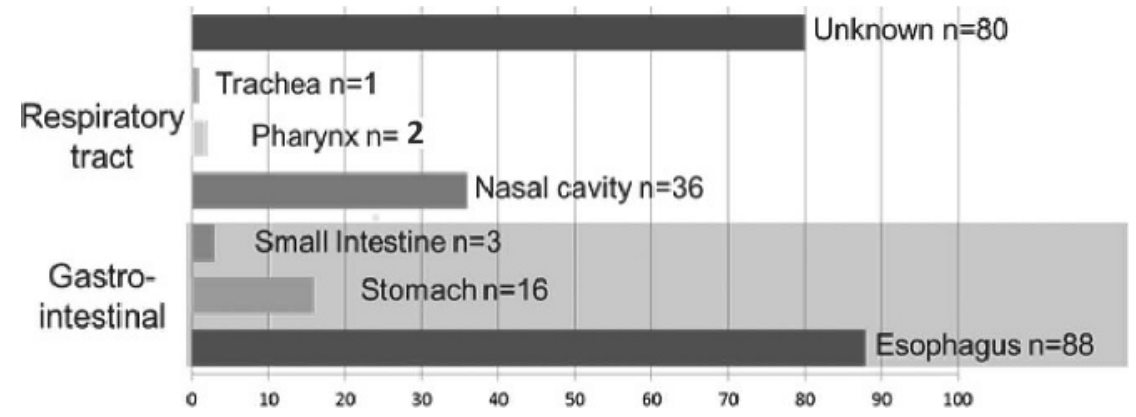

FIGURE 2. Bar graph representing the anatomical area of complication. 


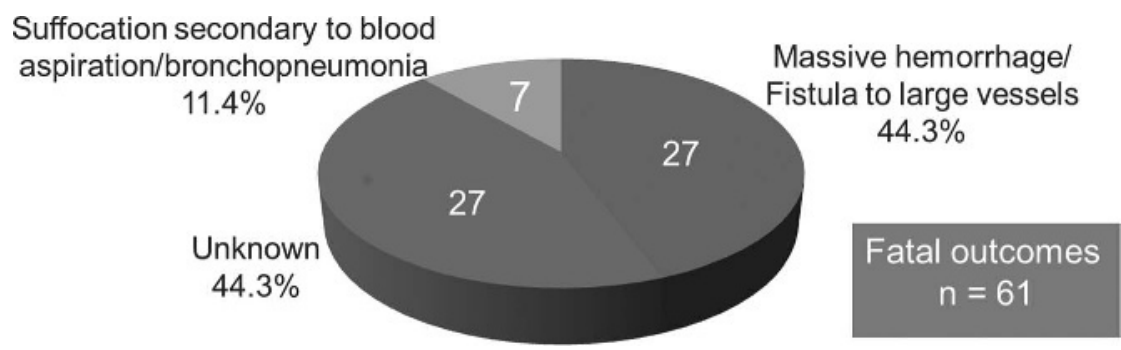

FIGURE 3. Pie chart showing the distribution and percentage of reported causes of death and the number of fatal outcomes.

referral to a tertiary care facility, or delayed anesthesia because of filled stomach can all contribute to complications. ${ }^{4}$ Severe tissue damage can occur in 2 hours with delayed complications. It should be noted that, even when the button battery is removed, associated complications may occur with delayed presentation ${ }^{26,27}$ such as tracheo-esophageal fistula that has been reported 6 days after removal and hemorrhage that has also been reported 18 days after the endoscopic removal due to the formation of an aortoesophageal fistula, and both resulted in death. ${ }^{10}$ A patient with Down syndrome was reported to have a vascular ring that compressed the posterior wall of the esophagus; therefore, the esophageal erosion into the surrounding arterial structures, a week after the removal of the ingested battery, resulted in fatal outcome. ${ }^{28}$

Parents, caregivers, and physicians should be aware of the potential hazards of BBI and consider the possibility of ingestion.

\section{CONCLUSIONS}

This exhaustive literature analysis demonstrates that BBI generally runs a benign course; however, if it is lodged in the esophagus, severe tissue injury can occur in only 2 hours. ${ }^{4}$ Children younger than 6 years are the most prone to BBI, with lithium batteries of $20 \mathrm{~mm}$ or larger in diameter associated with complications. Surgery for BBI may be necessary once a complication has occurred and focuses on management of the complication. Complications after BBI are low and are estimated to be $0.165 \%$. Lethal outcomes are also associated with BBI and are $0.04 \%$. The esophagus is the most endangered organ in the gastrointestinal system with regard to the complications, but vascular involvement after battery erosion through the mucosal surface adjacent to major vascular structures is more often fatal. Preventive measures are necessary to avoid severe complications and death. ${ }^{29-31}$

\section{REFERENCES}

1. Sharpe SJ, Rochette LM, Smith GA. Pediatric battery-related emergency department visits in the United States 1990-2009. Pediatrics. 2012;129: 1111-1117.

2. Soccorso G, Grossman O, Martinelli M, et al. $20 \mathrm{~mm}$ lithium button battery causing an oesophageal perforation in a toddler: lessons in diagnosis and treatment. Arch Dis Child. 2012;97:746-747.

3. Anand TS, Kumar S, Wadhwa V, et al. Rare case of spontaneous closure of tracheo-esophageal fistula secondary to disc battery ingestion. Int J Pediatr Otorhinolaryngol. 2002;63:57-59.

4. Litovitz T, Whitaker N, Clark L, et al. Emerging battery-ingestion hazard: clinical implications. Pediatrics. 2010;125:1168-1177.

5. Garey CL, Laituri CA, Kaye AJ, et al. Esophageal perforation in children: a review of one institution's experience. J Surg Res. 2010;164:13-17.

6. Litovitz T, Whitaker N, Clark L. Preventing battery ingestions: an analysis of 8648 cases. Pediatrics. 2010;125:1178-1183.
7. Gopal M, Westgarth-Taylor C, Loveland J. Repair of tracheo-oesophageal fistula secondary to button battery ingestion: a combined cervical and median sternotomy approach. Afr J Paediatr Surg. 2015; 12:91-93

8. Jarugula R, Dorofaeff T. Oesophageal button battery injuries: think again Emerg Med Australas. 2011;23:220-223.

9. Samad L, Ali M, Ramzi H. Button battery ingestion: hazards of esophageal impaction. J Pediatr Surg. 1999;34:1527-1531.

10. Ferrante J, O'Brien C, Osterhout C, et al. Injuries from batteries among children aged $<13$ years - United States, 1995-2010. MMWR Morb Mortal Wkly Rep. 2012;61:661-666.

11. Yardeni D, Yardeni H, Coran AG, et al. Severe esophageal damage due to button battery ingestion: can it be prevented? Pediatr Surg Int. 2004;20: 496-501.

12. Chan YL, Chang SS, Kao KL, et al. Button battery ingestion: an analysis of 25 cases. Chang Gung Med J. 2002;25:169-174.

13. Buttazzoni E, Gregori D, Paoli B, et al. Symptoms associated with button batteries injuries in children: an epidemiological review. Int J Pediatr Otorhinolaryngol. 2015;79:2200-2207.

14. Kim SH, Keum B, Chun HJ. Drooling, irritability, and refusal to eat in a 22-month-old child. Button battery ingestion. Gastroenterology. 2015;149:544-545

15. Alam E, Mourad M, Akel S, et al. A case of battery ingestion in a pediatric patient: what is its importance?. Case Rep Pediatr. 2015; 2015:345050

16. Mortensen A, Hansen NF, Schiødt OM. Fatal aortoesophageal fistula caused by button battery ingestion in a 1-year-old child. Am J Emerg Med. 2010;28:984.e5-984.e6.

17. Wurzel DF, Masters IB, Choo KL, et al. A case for early bronchoscopic airway assessment after disc battery ingestion. Pediatr Pulmonol. 2014;49: E72-E74.

18. Simonin M, D'Agostino I, Lebreton M, et al. Bilateral vocal palsy following coin cell lithium battery ingestion: a case report and review. Eur J Pediatr. 2013;172:991-993.

19. Bernstein JM, Burrows SA, Saunders MW. Lodged oesophageal button battery masquerading as a coin: an unusual cause of bilateral vocal cord paralysis. Emerg Med J. 2007; 24:e15.

20. Lin VY, Daniel SJ, Papsin BC. Button batteries in the ear, nose and upper aerodigestive tract. Int J Pediatr Otorhinolaryngol. 2004;68: 473-479.

21. Elloy MD, Worley GA, Bailey CM. Foreign body inhalation: a case of mistaken identity? J Emerg Med. 2010;38: 499-501.

22. Fuentes S, Cano I, Benavent MI, et al. Severe esophageal injuries caused by accidental button battery ingestion in children. J Emerg Trauma Shock. 2014;7:316-321.

23. Kalyanshettar S, Patil S, Upadhye G. Button battery ingestion-case report and review. J Clin Diagn Res. 2014;8:PD01-PD02. 
24. Gohil R, Culshaw J, Jackson P, et al. Accidental button battery ingestion presenting as croup. J Laryngol Otol. 2014;128:292-295.

25. Brown JC, Murray KF, Javid PJ. Hidden attraction: a menacing meal of magnets and batteries. J Emerg Med. 2012;43:266-269.

26. Mohan P, Gondu GR, Narasimhan M, et al. Button battery ingestion in children — what one needs to know? Indian J Gastroenterol. 2014;33: 385-386.

27. Liao AY, McDonald D. Oesophageal complication from button battery ingestion in an infant. J Paediatr Child Health. 2013;49: $330-332$.
28. Mercer RW, Schwartz MC, Stephany J, et al. Vascular ring complicates accidental button battery ingestion. Clin Imaging. 2015;39:510-512.

29. Liao W, Wen G, Zhang X. Button battery intake as foreign body in Chinese children: review of case reports and the literature. Pediatr Emerg Care. 2015;31:412-415.

30. LaFrance DR, Traylor JG Jr, Jin L. Aspiration pneumonia and esophagotracheal fistula secondary to button battery ingestion. Forensic Sci Med Pathol. 2011;7:283-286.

31. Tong MC, Ying SY, van Hasselt CA. Nasal foreign bodies in children. Int J Pediatr Otorhinolaryngol. 1996;35:207-211. 